\title{
How free are Canada's unmuzzled scientists?
}

$\mathrm{T}$ he muzzles were coming off, or at least that's how it seemed four months ago when Canada's new Liberal government sanctioned federal scientists to "speak freely" after a decade of increasing restriction and secrecy under the Conservatives. A flurry of hopeful reports followed: top ministers granted interviews, scientists at Environment Canada and Fisheries and Oceans Canada celebrated new freedoms, and journalists got answers without a runaround. But it appears the Liberals' sunny ways haven't reached Health Canada, which still keeps scientists on a short leash.

Communications policies adopted under the former Conservative government "have not changed," according to Health Canada's chief of media relations, Eric Morrissette. Virtually all communications are vetted by media relations staff, and in most cases, they provide written statements instead of direct access to experts. Morrissette claims that's all most journalists request. "We have always made our scientists and researchers available to the media and the public to discuss the science behind their work."

Those researchers told a different story, however, in a 2013 survey conducted by the Professional Institute of the Public Service of Canada (PIPSC), the union representing over 15000 federal scientists. Ninety-four percent of Health Canada scientists said they were not allowed to speak freely to the media about their work. They also reported the highest rates of interference by management with manuscripts and conference presentations, as well as requests to exclude or alter information in government documents for nonscientific reasons.

According to PIPSC, no scientific reasons have been provided to justify restricting scientists' access to media, and the "big chill" described by the union in 2013 has yet to thaw under a new government.

CMAJ emailed 25 Health Canada researchers - many senior scientists

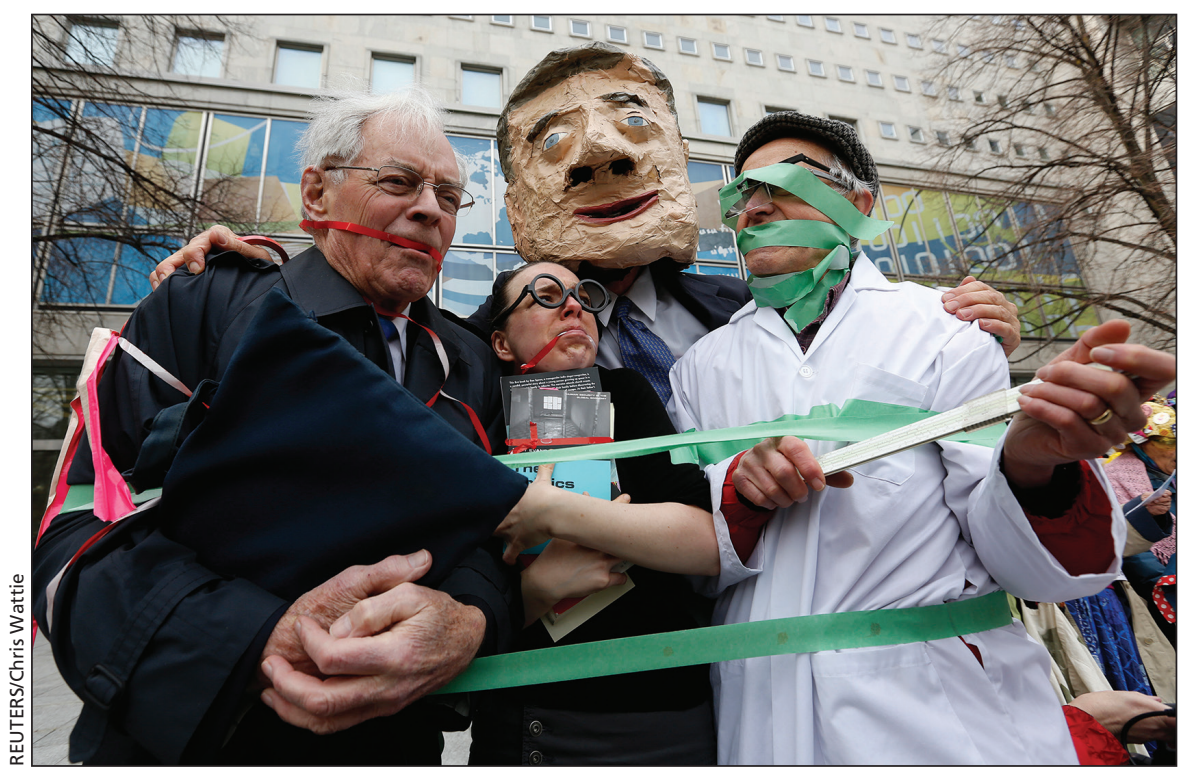

Despite protests, such as this one in 2013 , and a new federal government, many scientists still suffer under "draconian" communications policies, say watchdog groups.

- across nine directorates asking if they were able to discuss their work without the involvement of communications staff. Two declined to comment and the rest did not respond, although seven of those did send receipts indicating that they had read the message.

\section{Unmuzzling not enough}

"I think a lot of scientists are still confused as to what they can and can't do, especially following 10 years of having these very restrictive policies," says Katie Gibbs, executive director of the science-advocacy group Evidence for Democracy.

Her 2014 study of media policies at 16 federal departments gave Health Canada a failing grade for safeguards against political interference, and concluded that Canadian scientists face far more restrictions on sharing research than their American counterparts.

"I' $m$ not convinced that an announcement saying, 'You're free to talk,' is going to be enough to change the culture," Gibbs says.

Concerns about muzzling at Health Canada are longstanding, dating back to the Liberals under Paul Martin, she adds. "A lot of the government scientists that I've talked to say the muzzling started [first] in Health Canada."

In a Mar. 9 open letter to Prime Minister Justin Trudeau, PIPSC and Evidence for Democracy warned that "the scale of communication restriction under the previous government has left a legacy of draconian communication policies in many departments."

According to the groups, new policies are needed to "clarify the rules for government scientists, protect the integrity of their research and make it harder for future governments to muzzle scientists."

They're calling for an overarching policy on science integrity that would ensure timely release of scientific information; affirm scientists' rights to speak publicly and have last eyes on communications documents about their research; and safeguard against scientific misconduct and undue commercial influence.

PIPSC wants these protections enshrined in federal scientists' collective agreements, and will begin new contract negotiations with the government this week. "Then if the rules are broken, there would be a grievance and actions that could be taken," 
explains Emily Watkins, special advisor to the president of the union.

According to Duff Conacher, cofounder of Democracy Watch, a nonpartisan citizen advocacy group, new top-down policies must be paired with training and clear agreements on interpretation for researchers and managers. Otherwise, "policies are just vague words on paper that can be interpreted in different ways," he says.

Conacher notes that many preexisting communications policies "are not clear," so senior officials can change interpretations to suit their needs.

It's not surprising scientists are unwilling to speak out in such an environment, he adds. "People with mortgages and kids and financial demands are not going to stick their necks out without clear lines and knowing for sure they're protected."

In the meantime, "there are not a lot of incentives for the Liberals to actually change the policy until the media starts covering the fact that the announcement was not actually a policy change." - Lauren Vogel, CMAJ

CMAJ 2016. DOI:10.1503/cmaj.109-5251

\section{"Irresponsible" not to adopt national hepatitis plan}

$\mathrm{F}$ ears about the high cost of hepatitis drug treatment must not delay action on a pan-Canadian hepatitis strategy, a coalition of 35 health groups charged in a statement released Mar. 10.

Action Hepatitis Canada (AHC), which includes the Canadian AIDS Society and the Canadian Liver Foundation, wants Ottawa to act now on a 2014 World Health Organization resolution urging member states to adopt national hepatitis plans similar to those already implemented by Australia, France, the United Kingdom and the United States.

"National strategies in these countries promote prevention and screening, as well as price controls for $\mathrm{HCV}$ [hepatitis $\mathrm{C}$ virus] medicines," says Patricia Bacon, chair of the AHC's steering and executive committees. A national hepatitis strategy would result in higher treatment rates, improved prevention strategies, higher treatment retention, fewer treatment disparities and new pharmaceutical treatments moving faster to market, she says.

Hepatitis is not a small problem, Bacon emphasizes. According to the Canadian Liver Foundation, more than 500000 Canadians are likely chronically infected with hepatitis B or hepatitis C.

In a Jan. 25 statement, AHC also asked the federal government to take steps to curb the expense of new hepatitis medicines, some of which cost up to $\$ 60000$ for the complete treatment. The coalition wants the federal government to force down prices through measures such as bulk buying.

"Manufacturers of new HCV treatments are profiting at rates that are vastly disproportionate to their investment or to any reasonable expectation of commercial gain," the AHC charged.
"In the case of new HCV drugs, the prices have been set so high that governments and private payers cannot afford to treat all those who would benefit."

Many provincial formularies list $\mathrm{HCV}$ drugs but severely curtail access due to the cost.

The coalition would also like to see a national strategy to promote testing for everyone born between 1945 and 1975. "Nearly half of the Canadians who are living with $\mathrm{HCV}$ are unaware of their infection, and of those who are aware of their infection, too few are being treated to cure the disease," Bacon says. "At these low rates of diagnosis and treatment, $\mathrm{HCV}$ rates will continue to rise as will health care costs, due to expensive treatment for liver failure and liver cancer, such as liver transplantation."

Hepatologist Dr. Morris Sherman, chair of the Canadian Liver Foundation, agrees a national strategy is urgently needed.

"The Canadian government needs to understand that if not tackled today, both hepatitis $\mathrm{B}$ and $\mathrm{C}$ will be major burdens on the health care system in the next 20 years, as today's patients will suffer complications, develop liver cancer or require liver transplants." Sherman says liver cancer is most frequently a result of hepatitis $\mathrm{B}$ and $\mathrm{C}$, and its incidence is increasing more rapidly than any other cancer. "Proper care can prevent or cure this cancer, but due to the lack of a national strategy, the majority of patients who develop liver cancer will die from their disease."

Adam Cook, a hepatitis policy researcher for the Toronto-based Canadian Treatment Action Council, notes that the Public Health Agency of Canada
(PHAC) faces resistance from provincial and territorial officials. "The provinces are not taking the lead on this, because the increased screening increases the number of diagnoses, which increases the cost of treatment."

PHAC's deputy chief public health officer, Dr. Theresa Tam, acknowledges that although a federal framework for action on hepatitis has been in place since 2009, screening guidelines proposed by the agency in 2014 were retracted from public release at the urging of provincial and territorial representatives to the Pan-Canadian Public Health Network Council. "If you screen, you have to follow-up," Tam says. "And that really means treatment."

In the face of provincial and territorial resistance to screening, PHAC has referred the issue to the Canadian Task Force on Preventive Health Care, which will study the case for screening in greater detail, Tam says.

In the long run, screening and treatment will save money, according to a study published Jan. 12, 2015, in CMAJ by Dr. Jordan Feld, a clinician-scientist at the Toronto Western Hospital Francis Family Liver Clinic, and researchers at PHAC and the University of Toronto.

"There are very good data available now confirming there will be massive consequences if we don't act now," Feld says. "The failure to adopt screening guidelines is completely irresponsible. And it is terrible that we do not have a national strategy like those adopted in many other countries and recommended by the World Health Organization." Paul Webster, Toronto, Ont.

CMAJ 2016. DOI:10.1503/cmaj.109-5248 